This is a self-archived version of an original article. This version may differ from the original in pagination and typographic details.

Author(s): Lahtinen, Elmeri; Kukkonen, Esa; Kinnunen, Virva; Lahtinen, Manu; Kinnunen,
Kimmo; Suvanto, Sari; Väisänen, Ari; Haukka, Matti

Title: Gold Nanoparticles on 3D-Printed Filters : From Waste to Catalysts

Year: 2019

Version: Published version

Copyright: @ 2019 American Chemical Society

Rights: $C C$ BY 4.0

Rights url: https://creativecommons.org/licenses/by/4.0/

Please cite the original version:

Lahtinen, E., Kukkonen, E., Kinnunen, V., Lahtinen, M., Kinnunen, K., Suvanto, S., Väisänen, A., \& Haukka, M. (2019). Gold Nanoparticles on 3D-Printed Filters : From Waste to Catalysts. ACS Omega, 4(16), 16891-16898. https://doi.org/10.1021/acsomega.9b02113 


\title{
Gold Nanoparticles on 3D-Printed Filters: From Waste to Catalysts
}

\author{
Elmeri Lahtinen, ${ }^{\dagger}$ Esa Kukkonen, ${ }^{\dagger}$ Virva Kinnunen, ${ }^{\dagger}$ Manu Lahtinen, ${ }^{\dagger}$ Kil Kimmo Kinnunen, ${ }^{\dagger}$ \\ Sari Suvanto, ${ }^{\S}$ Ari Väisänen, ${ }^{\dagger}$ and Matti Haukka* ${ }^{\dagger}{ }^{\circ}$ \\ ${ }^{\dagger}$ Department of Chemistry and ${ }^{\ddagger}$ Department of Physics, Nanoscience Center, University of Jyväskylä, P.O. Box 35, Jyväskylä \\ FI-40014, Finland \\ ${ }^{\S}$ Department of Chemistry, University of Eastern Finland, P.O. Box 111, Joensuu FI-80101, Finland
}

\section{Supporting Information}

\begin{abstract}
Three-dimensionally printed solid but highly porous polyamide-12 (PA12) plate-like filters were used as selective adsorbents for capturing tetrachloroaurate from acidic solutions and leachates to prepare PA12-Au composite catalysts. The polyamide-adsorbed tetrachloroaurate can be readily reduced to gold nanoparticles by using sodium borohydride, ascorbic acid, hydrogen peroxide, UV light, or by heating. All reduction methods led to polyamide-anchored nanoparticles with an even size distribution and high dispersion. The particle sizes were somewhat dependent on the reduction method, but the average diameters were typically about $20 \mathrm{~nm}$. Particle sizes were determined by using a combination of single-particle inductively coupled plasma mass spectrometry, helium ion microscopy, and powder X-ray diffraction. Dispersion of the particles was analyzed by scanning

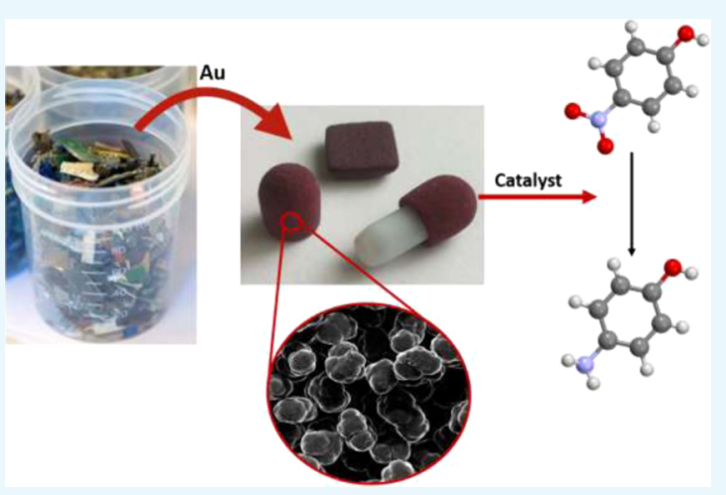
electron microscopy with energy-dispersive spectroscopy. Due to the high adsorption selectivity of polyamide-12 toward tetrachloroaurate, the three-dimensional-printed filters were first used as selective gold scavengers for the acidic leachate of electronicwaste (WEEE). The supported nanoparticles were then generated directly on the filter via a simple reduction step. These objects were used as catalysts for the reduction of 4-nitrophenol to 4-aminophenol. The described method provides a direct route from waste to catalysts. The selective laser sintering method can be used to customize the flow properties of the catalytically active filter object, which allows the optimization of the porous catalytic object to meet the requirements of catalytic processes.
\end{abstract}

\section{INTRODUCTION}

Gold nanoparticles have received an immense amount of attention during the past decades as they possess a range of fascinating properties and can be used for a variety of different applications. ${ }^{1-4}$ Especially gold-nanoparticle-mediated catalysis has emerged as a promising application. ${ }^{5-8}$ However, the use of gold nanoparticles as a suspension is problematic due to challenges faced in handling and recovering the particles. Therefore, immobilization of nanoparticles onto different polymers, ${ }^{9-11}$ resins, ${ }^{12,13}$ and even gels ${ }^{14}$ has been suggested as a potential solution to this problem. These solutions often rely on the use of novel or expensive materials that lack selectivity toward gold and therefore need to be prepared by using pure gold solutions. The use of a material with high selectivity toward gold could solve this issue as even goldcontaining waste could be used as a source for gold nanoparticles. Additionally, the previously reported immobilization methods often lack possibilities to control the shape, size, and flow properties of the supporting matrix. This, in turn, sets limitations to their usability in different types of reactions and flow environments.

Polyamide-12 (PA12) has been previously reported to have a high adsorption selectivity toward gold, as tetrachloroaurate, from acidic waste electrical and electronic equipment (WEEE) leachate. ${ }^{15}$ The captured tetrachloroaurate can be removed from polyamide by a simple elution step, which allows PA12 to be used as a reusable scavenger material. However, it is also possible to reduce the captured tetrachloroaurate to zerovalent gold directly on the polymer surface. In other words, the reduction process produces polyamide-anchored gold nanoparticles. ${ }^{11}$ The reduced gold particles are firmly attached onto the polyamide support, which make the metallized materials potential catalysts. This approach opens up a route for the preparation of supported nanoparticle catalysts directly from waste materials.

Three-dimensional (3D) printing enables the alteration of the shape and size of the nanoparticle-bearing objects. It is also possible to fabricate flow channels into the printed objects. This has been previously demonstrated with methods such as stereolithography and ink-jet printing. ${ }^{16,17}$ However, these methods produce surfaces that are not inherently porous. Furthermore, they also often require specifically customized

Received: July 9, 2019

Accepted: August 29, 2019 
printing materials. These problems can be avoided by using powder-based 3D-printing methods, such as selective laser sintering (SLS). With the SLS technique, it is possible to produce objects that are inherently porous. In SLS-printing, small particles with a typical diameter of $50-100 \mu \mathrm{m}$ are fused together by a laser, which gives control over the physical characteristics such as the porosity and mechanical strength of the printed material by fine-tuning the printing parameters such as laser power, exposure time, and printing temperature. ${ }^{18-22}$ When the particles are sintered in such a way that only their surfaces are partially melted, a solid structure containing accessible voids between the sintered grains is obtained. $^{15,18,23}$ Also, a wide range of chemically active printing materials can be used without complicated preprocessing steps ranging from functional polymers to mixtures of functional additives and supporting polymer matrices. ${ }^{23,24}$

In this paper, SLS 3D-printed PA12 filters were functionalized into PA12-Au composites by gold adsorption followed by reduction. The gold was adsorbed as tetrachloroaurate, from either acidic leachate of WEEE or a synthetic tetrachloroaurate solution. The reduction and formation of gold nanoparticles with various sizes were investigated with helium ion microscopy (HIM), scanning electron microscopy energy-dispersive spectroscopy (SEM-EDS), powder X-ray diffraction (XRD), and single-particle inductively coupled plasma mass spectrometry (SP-ICP-MS). A range of different reduction methods were used to investigate their impact on the particle size. The autoreduction process with no specific reduction agent was also followed. The catalytic activity of the supported gold nanoparticle filters was tested in the reduction of 4-nitrophenol to 4-aminophenol, which is a commonly used model reaction for gold-nanoparticle-mediated catalysis. ${ }^{25-27}$

\section{RESULTS AND DISCUSSION}

The porous SLS 3D-printed plate-like filters were fabricated using a Sharebot SnowWhite 3D printer, using PA12 powder consisting of c.a. $50 \mu \mathrm{m}$ diameter particles as printing material. After the printing process, the filters were carefully cleaned of any unsintered powder and adsorption of tetrachloroaurate was performed either from a synthetic solution or from acidleached printed circuit board (PCB) waste. After the adsorption, the SLS 3D-printed filters were washed extensively with water before being used in reduction experiments. Even though the samples used for the studies were simple plateshaped objects, different shapes and forms can also be produced and functionalized with gold nanoparticles (Figure S1).

The SLS 3D-printed PA12-Au filters were reduced using a variety of different reducing agents. First, PA12-Au filters were treated with $20 \mathrm{~mL}$ of $0.5 \mathrm{M} \mathrm{NaBH}_{4}$. By changing the reduction time between 1 and $15 \mathrm{~min}$, the color of the resulting PA12-Au filter could be altered. The shorter contact times led to filter plates with a red to light purple color, whereas longer contact times led to dark purple filters (Figure 1a). The color changes indicated changes in the nanoparticle sizes. $\mathrm{NaBH}_{4}$ reduction was also carried out for PA12-Au filters, where the gold was adsorbed from acid leachate of WEEE (Figure S2, see the Experimental Section). The resulting metallized filters were identical to the ones obtained by using pure tetrachloroaurate solution. The results show that it is possible to use electronic waste as a gold source for supported nanoparticles.

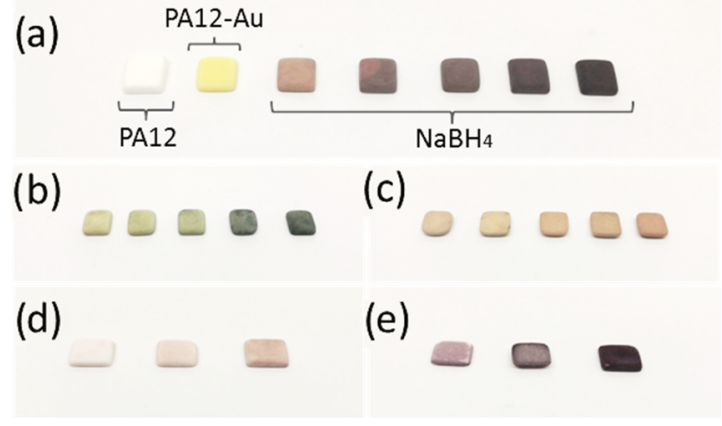

Figure 1. Images of SLS 3D-printed PA12 filters $\left(10 \times 10 \times 2 \mathrm{~mm}^{3}\right)$. (a) Pure filter (PA12) and a filter immediately after gold adsorption (PA12-Au). $\mathrm{NaBH}_{4}: \mathrm{PA}_{12}-\mathrm{Au}$ filters reduced with $0.5 \mathrm{M} \mathrm{NaBH}_{4}$ for $1,3,5,10$, and $15 \mathrm{~min}$, respectively. (b) PA12-Au filters reduced with $0.5 \mathrm{M}$ ascorbic acid for $1,3,5,10$, and $15 \mathrm{~min}$, respectively. (c) PA12-Au filters reduced with $30 \% \mathrm{H}_{2} \mathrm{O}_{2}$ for 5, 10, 15, 30, and 60 min, respectively. (d) PA12-Au filters reduced by using UV light (405 nm) for 20, 40, and $60 \mathrm{~min}$. (e) PA12-Au filters reduced by heating them in the oven $\left(110^{\circ} \mathrm{C}\right)$ for 30,60 , and $90 \mathrm{~min}$.

The second tested reduction method, that is, reduction with ascorbic acid, yielded gray to greenish PA12-Au filters. Also, in this case, the intensity of the color was dependent on the reduction time (Figure $1 \mathrm{~b}$ ). However, after the reduction, the color of the filters started to change to purple over a longer period of storage, typically over several days. The next method of reduction was more unconventional as it included treating the PA12-Au filter with hydrogen peroxide. Hydrogen peroxide is known to produce gold nanoparticles ${ }^{28}$ and in the case of SLS 3D-printed PA12-Au filters, it resulted in filters with red to light brown colors (Figure 1c). The last two methods tested were treating the filters with UV light (405 $\mathrm{nm}$ ) and heating them in the oven at $110{ }^{\circ} \mathrm{C}$, respectively. Both methods yielded PA12-Au filters with a red to purple color. In general, the heating treatment produced a much more intense color than the light-induced reduction (Figure 1d,e). However, it should be noted that even storing the PA12-Au filters at room temperature in ambient light was enough for slow conversion of the adsorbed gold into nanoparticles. This was observed as the color of the filters slowly turned light purple over an extended period of time.

HIM imaging of the PA12-Au samples was conducted to study the nanoparticle sizes and their distribution within the SLS 3D-printed filters. Figure 2 shows the HIM images of $\mathrm{PA12}-\mathrm{Au}$ filters prepared from synthetic tetrachloroaurate solution and reduced with $\mathrm{H}_{2} \mathrm{O}_{2}$ (Figure 2a,b) and ascorbic acid-reduced PA12-Au filters prepared from acidic WEEE leachate (Figure 2c,d). From the zoomed-out images, it can be seen that distributions of the gold nanoparticles on the surfaces of the fused PA12 particles in PA12-Au filters are rather even for both of the samples. As it has been previously shown, SLS 3D-printing can be used to fabricate solid but highly porous structures, where a fluid can flow through the voids between the partially fused particles. ${ }^{23,24}$ This particle-like structure can also be seen in Figure 2a,c and in Figure S3 given as a Supporting Information. Furthermore, the gold nanoparticles are attached only on the surfaces of the fused particles and they are not capsulated by the polymer. This means that the gold nanoparticles are also distributed in the inner structure of the printed objects, but they are still able to interact with fluids running through the object material. The more detailed HIM images (Figure 2b,d) confirm the even spatial distribution of 

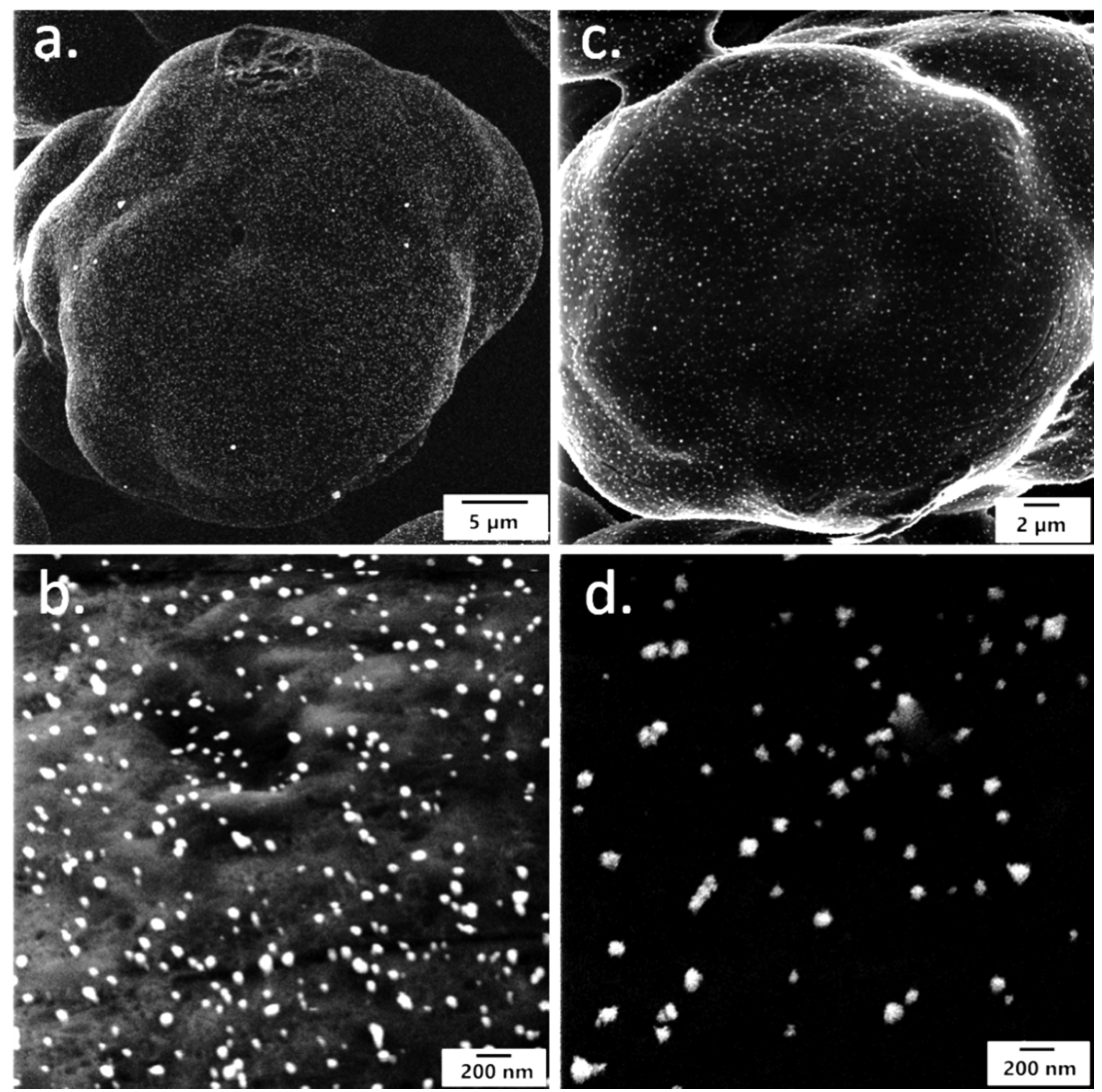

Figure 2. HIM images of the surfaces of the $\mathrm{H}_{2} \mathrm{O}_{2}$-reduced PA12-Au filters prepared using synthetic tetrachloroaurate solution (a, b) and of the ascorbic acid-reduced, WEEE-derived PA12-Au filters (c, d).

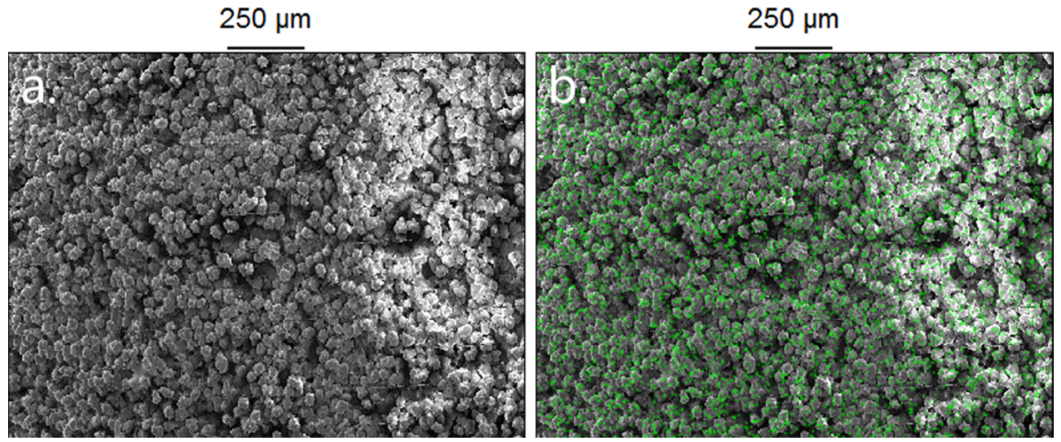

Figure 3. SEM-EDS image of the analyzed area of the ascorbic acid-reduced PA12-Au sample (a). Overlaid image of the obtained gold spectral image (green) and the initial image of the analyzed area (b).
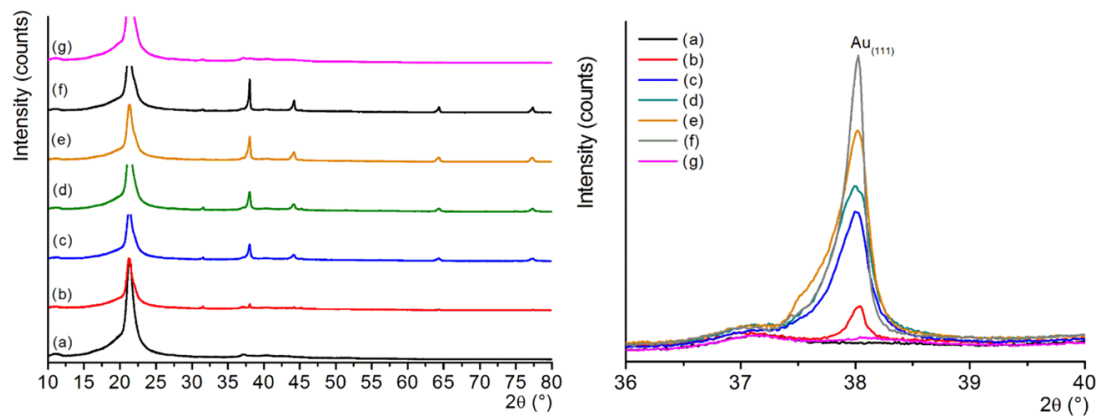

Figure 4. Left: XRD patterns of PA12-Au filters with different reducing agents used: (a) reference filter without Au; PA12-Au reduced with (b) UV light, (c) $\mathrm{NaBH}_{4}$, (d) heating, (e) ascorbic acid, and (f) $\mathrm{H}_{2} \mathrm{O}_{2}$; and (g) PA12-Au sample, where gold is derived from WEEE and reduced with $\mathrm{NaBH}_{4}$. Right: zoomed $2 \theta$ range showing the $\mathrm{Au}_{(111)}$ peak on each pattern. 
the gold particles. The even size distribution of the nanoparticles can also be seen in Figures $2 \mathrm{~b}$,d. Even if HIM is not the optimal method for particle size analysis, it clearly indicates that most of the nanoparticles are within the range of $10-100 \mathrm{~nm}$ in both samples. The HIM images of the samples reduced by other methods are given in the Supporting Information (Figures S4 and S5).

The even distribution of the gold nanoparticles on the surfaces of the SLS 3D-printed objects is somewhat surprising since the nanoparticles are not end-capped with ligands. However, it could be reasoned that interactions between gold and the functional groups of the PA12 polymer are responsible for the high dispersion and even size distribution. This has also been suggested as the reason for the even distribution of gold nanoparticles on PA66 surfaces. ${ }^{11}$ Most likely, the amide groups of PA12 provide sufficiently strong interactions with the nanoparticles to prevent excessive agglomeration.

Additional analyses for the dispersion of the gold nanoparticles on the printed filters were carried out by performing spectral imaging using SEM-EDS. The ascorbic acid-reduced PA12-Au filter was covered with silver particles prior to SEMEDS analysis. Spectral imaging was then performed, and the results are shown in Figure 3. The image of the analyzed area of the sample (Figure 3a) is overlaid with the spectral imaging map received for the gold (Figure $3 b$ ). Together with the HIM imaging results, the SEM-EDS analysis confirms that the distribution of the gold nanoparticles on the PA12-Au filters is uniform.

Powder X-ray diffraction (XRD) patterns of the PA12-Au filters are shown in Figure 4. All of the XRD patterns show characteristic peaks of the PA12 polymer matrix, which can be confirmed based on the peaks observed in the pattern of the reference filter of pristine PA12 (reference pattern for PA12 was not available in the PDF4 database ${ }^{29}$ ). In case of filters with reduced gold nanoparticles, the characteristic diffraction peaks at $38.1,44.39,64.62$, and $77.59^{\circ} 2 \theta$ could be assigned (PDF4 entry: 00-066-0091) ${ }^{2}$ to metallic gold in a facecentered cubic crystal system $(F m \overline{3} m)$. In addition to the characteristic peaks of PA12 and gold, there were no other peaks in the patterns, indicating that only gold was reduced onto the filters. This was also the case with the $\mathrm{NaBH}_{4}$-reduced sample where WEEE was used as the gold source. It means that the other metals present in the WEEE solution (e.g., $\mathrm{Cu}$, $\mathrm{Fe}, \mathrm{Al}$...) were not adsorbed to the PA12 filters. However, it should be noted that the gold content in that particular sample was also considerably lower, due to a much lower concentration of gold being available for adsorption from the acid-leached WEEE compared to the synthetic tetrachloroaurate solution. Comparison of the XRDs of the different reduction techniques revealed that the $\mathrm{H}_{2} \mathrm{O}_{2}$ reduction showed the highest intensity for gold particles, followed by others in the order of ascorbic acid $>$ heat treatment $\geq \mathrm{NaBH}_{4}>\mathrm{UV}$ light (Figure 4).

To get a coarse estimate of the dispersion of gold in the filter, the average crystallite size of the gold particles was estimated by the Scherrer method as shown in eq 1

$$
D=\frac{\kappa \lambda}{\beta_{\mathrm{s}} \cos \theta}
$$

in which $D$ is the average crystallite size, $K$ is the shapedependent Scherrer constant $(0.90$ for spherical crystallites with a cubic symmetry), $\lambda$ is the X-ray wavelength (1.5406 $\AA$ ), $\beta_{\mathrm{s}}$ is the full peak-width at half-maximum intensity (given in radians) corresponding to structural broadening (instrumental broadening taken into account), and $\theta$ is the diffraction angle. For each sample, the strongest Au peak (38.1 ${ }^{\circ} 2 \theta$ ) with Miller indices (111) was taken for an indicative crystal size analysis, and the resulting values are shown in the Supporting Information (Table S1). Generally, the average crystal size of gold particles ranged from 30 to $70 \mathrm{~nm}$. It is noticeable that UV light-treated and $\mathrm{H}_{2} \mathrm{O}_{2}$-treated samples exhibit similarsized particles, even though in terms of quantity they represent the two extremes of the series. In all the rest of the samples, the crystal size of gold is about the same $(\sim 30 \mathrm{~nm})$ regardless of the quantity of the gold phase per sample. However, it should be kept in mind that these results represent a rather qualitative estimation of the particle size as an accurate peak profile analysis of a low crystalline phase that is mixed with a lowcrystalline organic matrix is challenging for reasons such as the degree of peak overlap and uncertainties to define the proper peak profile tailing versus baseline signals. Second, the crystallographic crystal size analysis tends to skew on larger average sizes due the fact that larger particles have a somewhat higher diffraction power than the smaller ones. However, the XRD results are well in line with the HIM analyses above.

The SP-ICP-MS analyses were used to study further the size distribution of the nanoparticles. SP-ICP-MS is a highly sensitive method for the characterization of nanoparticles from solutions. Even if the leaching of gold from the goldfunctionalized filters was low, the removed particles could be analyzed. The nanoparticle size distribution diagram observed during the analysis is represented in Figure 5. The majority of

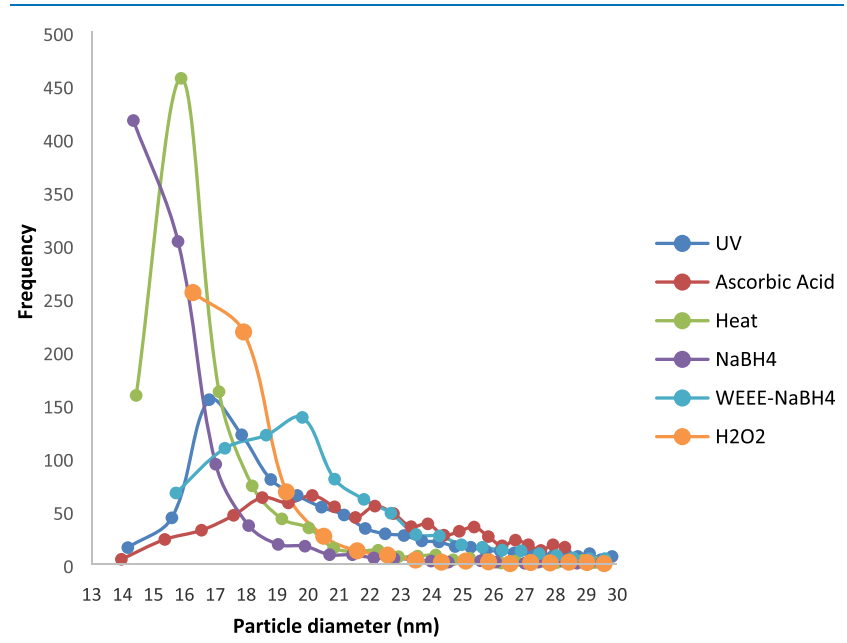

Figure 5. Nanoparticle size distribution diagram of the PA12-Au filters reduced with different methods obtained from the SP-ICP-MS measurement. The observed particle frequencies are not strictly comparable to each other due to different dilution factors and run times.

the observed particles were in the size range of $14-32 \mathrm{~nm}$ ( $\geq 90 \%$ detected particles). Typically, most of the nanoparticles observed appeared to have an average diameter of around 20 $\mathrm{nm}$. Among the different reduction methods, $\mathrm{NaBH}_{4}$ seems to lead to the smallest nanoparticles with average sizes of $16 \pm 1$ nm observed, while ascorbic acid, heating, and UV light led to average particle sizes of $20 \pm 5,20 \pm 4$, and $20 \pm 3 \mathrm{~nm}$, respectively. Reduction with $\mathrm{H}_{2} \mathrm{O}_{2}$ led to particles with an average diameter of $21 \pm 2 \mathrm{~nm}$. The PA12-Au filters where 
the $\left[\mathrm{AuCl}_{4}\right]^{-}$was adsorbed from the acidic WEEE leachate followed by reduction using $\mathrm{NaBH}_{4}$ produced nanoparticles of $21 \pm 4 \mathrm{~nm}$ diameter (Table S2).

As can be seen from the average diameters observed, most of the reduction methods led to PA12-Au filters having rather uniformly sized nanoparticles. In addition, the normal analytical uncertainty might explain the observed differences in the average diameters. Even the WEEE-derived PA12-Au filters possessed nanoparticles of around the same size than the other PA12-Au filters produced by using synthetic tetrachloroaurate solutions. Such results confirm the suitability of secondary gold sources for generating supported nanoparticles. The particle size distribution based on SP-ICP-MS results are in good agreement with the sizes of the nanoparticles observed in the HIM images (Figures 2, S4, and S5) and the results obtained by XRD (Figure 4 and Table S1). It should be emphasized that no severe leaching of gold was observed. This was tested by shaking the catalyst object vigorously in ultrapure water and analyzing the released Au-NPs by SPICP-MS. The amount of released $\mathrm{Au}$ was found to be at most $0.1 \mathrm{wt} \%$. The results of the leaching tests support further the firm attachment of gold nanoparticles on the PA12 matrix.

The catalytic activity of the gold nanoparticle-functionalized SLS 3D-printed filters was tested in the simple reduction of 4nitrophenol to 4-aminophenol in the presence of $\mathrm{NaBH}_{4}$ following the previously reported method. ${ }^{25}$ The completeness of the reactions were then determined by UV-vis spectroscopy. Based on the obtained results (Figure 6), it is evident

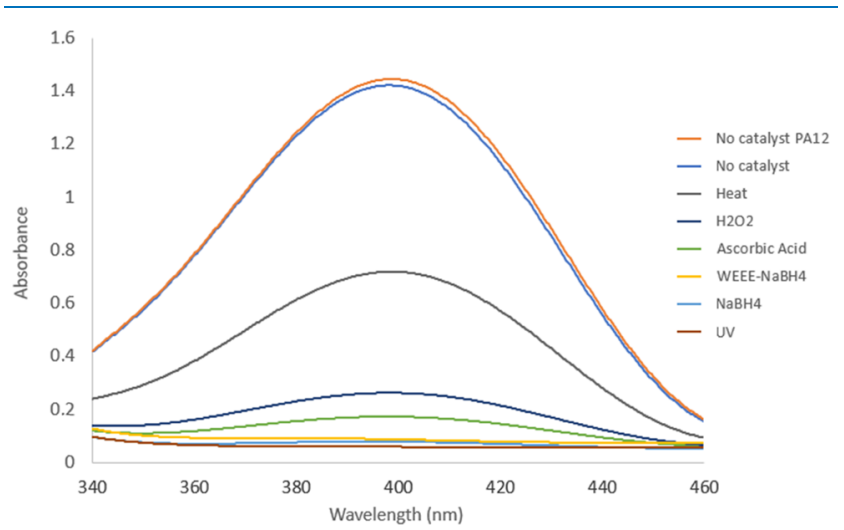

Figure 6. UV-vis results for the gold-catalyzed reduction of 4nitrophenol to 4-aminophenol in the presence of $\mathrm{NaBH}_{4}$.

that the PA12-Au filters are able to effectively catalyze the conversion. The solutions without Au catalysts show no signs of a reaction, whereas most PA12-Au filters have catalyzed the reactions to completeness within the $2 \mathrm{~h}$ reaction time. The filter treated by heating shows slightly deviating results compared to others. However, all of the reactions with the catalysts were found to reach completeness if let to react over a longer period of time. In addition to the simple plate-shaped PA12-Au filters, stir bar sleeve-shaped catalysts (Figure S1) were also tested and found to perform similar to the other filters tested.

The reusability of the catalysts was tested by performing 10 consecutive catalytic cycles with the PA12-Au filter reduced with $\mathrm{NaBH}_{4}$. No significant decrease in the catalytic activity was observed, which further shows the strong attachment of the gold nanoparticles onto the SLS 3D-printed PA12 filter. Additionally, the PA12-Au filter where gold was adsorbed from acid-leached WEEE, followed by reduction with $\mathrm{NaBH}_{4}$, was also tested $\left(\mathrm{WEEE}-\mathrm{NaBH}_{4}\right)$. The filter performed just like the ones prepared using pure tetrachloroaurate solution, further confirming that waste materials such as WEEE can be used as a feedstock for the preparation of gold nanoparticle catalysts.

\section{CONCLUSIONS}

In this paper, we introduce a method for manufacturing SLS 3D-printed polyamide-12 objects functionalized with gold nanoparticles. This can be achieved by adsorbing gold as tetrachloroaurate onto the polyamide- 12 matrix, followed by a reduction. A variety of reduction methods can be used to produce highly dispersed and evenly sized gold nanoparticles with an average diameter of around $20 \mathrm{~nm}$ on the polyamide filters. The functionalized filters can be used as effective catalysts in the reduction of 4-nitrophenol to 4-aminophenol. Since PA12 is a highly selective adsorbent for gold, it is possible to use various gold-containing solutions as the source of gold. This opens up a direct route from waste materials to catalysts. For example, the acidic leachate of circuit board waste can be used as the gold source for the preparation of PA12-supported gold nanoparticle catalysts with no additional purification steps and without any interference by the other metals. SLS-printing provides an attempting technique for preparing heterogeneous catalysts. The chemical activity can be optimized by the choice of the printing material, while the printing technique allows fine-tuning of the shape, size, porosity, and flow properties of the printed object. Although we have used SLS-printing for the preparation of catalysts with supported gold nanoparticles, the same approach can be extended to other metals as well. This can be achieved by replacing PA12 with another printing material that can selectively adsorb the desired metal.

\section{EXPERIMENTAL SECTION}

Chemicals and Materials. Hydrogen peroxide (AnalaR NORMAPUR) and ascorbic acid (AnalaR NORMAPUR) were purchased from VWR. Sodium borohydride (>98\%) was supplied by Acros Organics, and 4-nitrophenol (98\%), nitric acid ( $\geq 65 \%)$, and hydrochloric acid $(\geq 37 \%)$ were purchased from Merck. Polyamide-12 was obtained from ADVANC3D materials and used without any additional pretreatment. All chemicals were used as received.

3D-Printing of the PA12 Filters. The PA12 filters $(10 \times$ $10 \times 2 \mathrm{~mm}^{3}$ ) were printed using a Sharebot SnowWhite SLS $3 \mathrm{D}$ printer. Highly porous objects with good physical durability were obtained using the following parameters during the printing process: $161{ }^{\circ} \mathrm{C}$ environmental temperature, $40 \%$ laser power (a maximum of $14 \mathrm{~W}$ ), $2400 \mathrm{~mm} \mathrm{~s}^{-1}$ laser speed, and $0.1 \mathrm{~mm}$ layer height. The 3D-printed objects were thoroughly cleaned of any nonsintered powder after the printing process. No further pretreatment was performed prior to the gold adsorption experiments.

Adsorption of Tetrachloroaurate onto PA12 Filters. The gold was adsorbed as tetrachloroaurate onto the SLS 3Dprinted filters either from a synthetic solution or from acidleached PCB waste. The synthetic tetrachloroaurate solution was prepared by diluting a Perkin Elmer $1000 \mathrm{mg} \mathrm{L}^{-1}$ spectroscopy standard until the concentration of gold was around $200 \mathrm{mg} \mathrm{L}^{-1}$. The solution was adjusted to have $10 \mathrm{vol}$ $\% \mathrm{HCl}$. The PCB sample was prepared by ashing the milled 
PCB waste at $950{ }^{\circ} \mathrm{C}$ for $4 \mathrm{~h}$. The sample was then dissolved using ultrasound-assisted leaching with aqua regia. The leachate was diluted before the gold was adsorbed onto the 3D-printed filters. Both with synthetic and authentic solutions, the filter plates were kept in contact with the solution for $8 \mathrm{~h}$. This was done to ensure the saturation, even though the adsorption process itself is rather fast. ${ }^{15}$ After the adsorption, the filters were thoroughly washed with water. The PA12-Au objects, prepared from the synthetic tetrachloroaurate solution, were adjusted to possess around $0.5 \mathrm{wt} \%$ of gold. After the adsorption, the objects were reduced. The samples that were analyzed using the following methods were reduced using 0.5 $\mathrm{M} \mathrm{NaBH}_{4}, 0.5 \mathrm{M}$ ascorbic acid, $30 \% \mathrm{H}_{2} \mathrm{O}_{2}$ solution, UV light, or thermal treatment for $15 \mathrm{~min}\left(\mathrm{NaBH}_{4}\right.$ and ascorbic acid), $60 \mathrm{~min}\left(\mathrm{H}_{2} \mathrm{O}_{2}\right.$ and $\left.\mathrm{UV}\right)$, or $90 \mathrm{~min}$ (thermal treatment).

Helium Ion Microscopy. Imaging was performed with a Carl Zeiss ORION NanoFab helium ion microscope. The beam energy used was roughly $30 \mathrm{keV}$, and the beam current was set between 0.32 and $0.38 \mathrm{pA}$. The dwell time of the scans was altered between 0.2 and $50 \mu$ s for optimal picture quality. The working distance was generally around $6.2-8.3 \mathrm{~mm}$. Samples were not treated in any way before imaging aside from the use of pressurized air to clear any loose particles from the surfaces of the samples.

Scanning Electron Microscopy Energy-Dispersive XRay Spectroscopy. The SEM-EDS analysis was performed by using Hitachi $\mathrm{S}-4800$ field emission scanning electron microscopy with a Thermo Electron Noran System Sic EDS (NSS200) detector. The samples were coated with silver particles prior to analysis to overcome the challenges faced with nonconductive samples. An acceleration voltage of $10 \mathrm{kV}$ was used for the analysis. Around $10 \mathrm{~min}$ of spectral imaging data were gathered during the imaging process for the gold dispersion analysis.

Powder X-ray Diffractometry. X-ray powder diffraction patterns were measured by a PANalytical X'Pert PRO diffractometer in Bragg-Brentano geometry using $\mathrm{Cu} \mathrm{K} \alpha_{1}$ radiation (Johannsson type monochromator, $\lambda=1.5406 \AA$, 45 $\mathrm{kV}, 40 \mathrm{~mA}$ ). A sample filter was first set on a silicon filter (zero background signal filter) that was placed on a steel-made sample holder with a height-adjustable cavity. The pattern was recorded from a spinning sample by an X'Celerator detector in the $2 \theta$ range of $3-80^{\circ}$ with a step size of $0.017^{\circ}$ and a counting time of $400 \mathrm{~s}$ per step ( $4 \mathrm{~h} 10 \mathrm{~min}$ overall time). Diffraction data were processed with the Malvern Panalytical HighScore Plus v. 4.7 program. $^{30}$

Single-Particle Inductively Coupled Plasma Mass Spectrometry. SP-ICP-MS measurements were performed on a NexION350D ICP-MS spectrometer operating in the single-particle mode using the Syngistix Nano Application Module (PerkinElmer Inc., Massachusetts). Instrumental parameters are shown in Table 1 . The nebulizer gas flow was optimized to gain maximum response for ${ }^{197} \mathrm{Au}$. The sample uptake rate was measured daily by quantifying the mass of sample uptake after $3 \mathrm{~min}$ in duplicate. The transport efficiency (i.e., the fraction of nebulized sample entering the plasma) was determined using the particle size method. Citrate-stabilized 30 and $60 \mathrm{~nm}$ gold nanoparticles (NanoComposix, San Diego, CA) were used for particle calibration after dilution with ultrapure water with a resistivity of $18.2 \mathrm{M} \Omega \mathrm{cm}$ (UP-water, PURELAB Ultra, ELGA LabWater, Buckinghamshire, U.K.). Dissolved gold calibration solutions were prepared from a standard stock solution of $100 \mu \mathrm{g} \mathrm{mL}^{-1} \mathrm{Au}$ in $2 \% \mathrm{HCl}$ (Pure
Table 1. NexION350D Instrumental Parameters

\begin{tabular}{ll}
\multicolumn{1}{c}{ parameter } & \multicolumn{1}{c}{ condition } \\
nebulizer & ESI PFA concentric \\
spray chamber & baffled cyclonic, glass \\
injector & $1.8 \mathrm{~mm}$ i.d. sapphire \\
power & $1600 \mathrm{~W}$ \\
nebulizer gas flow & $0.97-0.99 \mathrm{~L} \mathrm{~min}^{-1}$ \\
sample uptake rate & $0.333-0.337 \mathrm{~g} \mathrm{~min}^{-1}$ \\
dwell time & $100 \mu \mathrm{S}$ \\
sampling time & $60-6000 \mathrm{~s}$ \\
transport efficiency & $6.38-6.73 \%$
\end{tabular}

Plus, Perkin Elmer, Massachusetts) by dilution in a thiourea solution ( $0.1 \mathrm{~mol} \%$ thiourea ( $\geq 99.0 \%$, VWR International, Pennsylvania), $2.4 \mathrm{vol} \% \mathrm{HCl}$, and 0.05 vol $\% \mathrm{HNO}_{3}$ ). Highpurity (Analpure) hydrochloric acid and nitric acid were obtained from Analytika spol. s r.o. (Prague, Chech Republic). All dilutions were performed gravimetrically.

All samples were placed in $50 \mathrm{~mL}$ polypropene containers and $20 \mathrm{~mL}$ of UP-water was added. The samples were vigorously shaken for $30 \mathrm{~s}$ for particle release. For every sample, at least three different dilutions were made with UPwater to minimize the contribution of dissolved signal possibly overlapping the particle signal. The sampling time was adjusted to $60-6000 \mathrm{~s}$ depending on the sample to gain a sufficient number of detected peaks for reliable particle concentration calculation ( $>500$ peaks). All dilutions were performed gravimetrically, and samples were analyzed as soon as possible after the initial sample preparation to minimize changes in the original sample composition over time.

The Syngistix Nano Application Module was used for data processing. The intensity of detected particles was related to the particle mass $(\mu \mathrm{g})$ using a particle calibration curve and transformed to the particle diameter $(\mathrm{nm})$ assuming a spherical particle geometry. The mean particle diameter and particle concentration for each sample were calculated as an average for the results obtained for different dilutions $(n=1-3)$ and replicate readings and were reported as average \pm standard deviation ( $1 \mathrm{~s}$ ). The instrumental drift causing the level of measured intensity to decrease over time was corrected with a drift correction standard (Pt $1 \mu \mathrm{g} \mathrm{kg}^{-1}$ in $1+1 \% \mathrm{HCl} / \mathrm{HNO}_{3}$ ). The total mass of particulate gold in the samples was calculated based on the measured sample particle concentration (particles/g) and mean particle diameter $(\mathrm{nm})$.

UV-Vis Spectroscopy. UV-vis spectra of the catalytically reduced 4-nitrophenol solutions were measured from 700 to $340 \mathrm{~nm}$ using a Perkin Elmer Lambda $25 \mathrm{UV} / \mathrm{Vis}-$ spectrophotometer. A slit of $1.0 \mathrm{~nm}$ was used with a scan speed of $240 \mathrm{~nm} \mathrm{~min}^{-1}$ and a data interval of $3.0 \mathrm{~nm}$. Ultrapure water was used as a reference sample in the reference cuvette.

Catalysis. A $0.1 \mathrm{mM}$ solution of 4-nitrophenol was prepared by dissolving roughly $7 \mathrm{mg}$ of 4-nitrophenol in 500 $\mathrm{mL}$ of deionized water. Next, $5 \mathrm{~mL}$ of the obtained solution was pipetted to eight small glass beakers, and $10 \mathrm{mg}$ of $\mathrm{NaBH}_{4}$ was added to each beaker to act as the reducing agent. Excess of $\mathrm{NaBH}_{4}$ was used to avoid any kind of effect the change of concentration of the reductant could have on the reaction. One PA12-Au filter each treated with a different gold reduction method (as described earlier) was placed in the beaker containing 4-nitrophenol and $\mathrm{NaBH}_{4}$. Two beakers, one containing just the starting material and the reductant and the other also containing the PA12 filter with no gold, acted as 
references. The mixtures were then stirred for $2 \mathrm{~h}$, even though many of the reactions could be seen to happen much faster. Excessive reaction time was chosen to further confirm that the reaction would not proceed without the catalyst. The reusability of the catalysts was determined by performing 10 reaction cycles with a PA12-Au filter that had been reduced using $\mathrm{NaBH}_{4}$. No significant drop in the catalytic activity was observed. Samples were then analyzed by using UV-vis spectroscopy.

\section{ASSOCIATED CONTENT}

\section{S Supporting Information}

The Supporting Information is available free of charge on the ACS Publications website at DOI: 10.1021/acsomega.9b02113.

Additional images of the PA12-Au objects; HIM images of the structure of the PA12-Au objects; XRD and SPICP-MS result tables (PDF)

\section{AUTHOR INFORMATION}

\section{Corresponding Author}

*E-mail: matti.o.haukka@jyu.fi.

\section{ORCID}

Elmeri Lahtinen: 0000-0002-8414-9915

Manu Lahtinen: 0000-0001-5561-3259

Matti Haukka: 0000-0002-6744-7208

\section{Author Contributions}

E.L. and E.K. printed the objects and performed the gold reduction and catalysis experiments as well as measured the UV-vis spectra. V.K. conducted the SP-ICP-MS measurements. M.L. performed the powder XRD analysis of the samples. K.K. and E.L. conducted the HIM imaging of the PA12-Au filters, while S.S. and E.L. performed the SEM-EDS imaging. M.H. and A.V. supervised the project. The initial manuscript was written by E.L. and E.K. and was then jointly revised by all authors.

\section{Notes}

The authors declare no competing financial interest.

\section{ACKNOWLEDGMENTS}

The funding received from the Centennial Foundation of Technology industries of Finland as well as the Jane and Aatos Erkko foundation is greatly appreciated. The research was also supported by the Academy of Finland (grant number: 295581 (M.H.)) and by the Department of Chemistry, University of Jyväskylä.

\section{REFERENCES}

(1) Giljohann, D. A.; Seferos, D. S.; Daniel, W. L.; Massich, M. D.; Patel, P. C.; Mirkin, C. A. Gold Nanoparticles for Biology and Medicine. Angew. Chem., Int. Ed. 2010, 49, 3280-3294.

(2) Boisselier, E.; Astruc, D. Gold Nanoparticles in Nanomedicine: Preparations, Imaging, Diagnostics, Therapies and Toxicity. Chem. Soc. Rev. 2009, 38, 1759-1782.

(3) Ghosh, P.; Han, G.; De, M.; Kim, C. K.; Rotello, V. M. Gold Nanoparticles in Delivery Applications. Adv. Drug Delivery Rev. 2008, 60, 1307-1315.

(4) Guo, S.; Wang, E. Synthesis and Electrochemical Applications of Gold Nanoparticles. Anal. Chim. Acta 2007, 598, 181-192.

(5) Corma, A.; Garcia, H. Supported Gold Nanoparticles as Catalysts for Organic Reactions. Chem. Soc. Rev. 2008, 37, 20962126.
(6) Chen, Y.; Qiu, J.; Wang, X.; Xiu, J. Preparation and Application of Highly Dispersed Gold Nanoparticles Supported on Silica for Catalytic Hydrogenation of Aromatic Nitro Compounds. J. Catal. 2006, 242, 227-230.

(7) Panigrahi, S.; Basu, S.; Praharaj, S.; Pande, S.; Jana, S.; Pal, A.; Ghosh, S. K.; Pal, T. Synthesis and Size-Selective Catalysis by Supported Gold Nanoparticles: Study on Heterogeneous and Homogeneous Catalytic Process. J. Phys. Chem. C 2007, 111, 4596-4605

(8) Tran, T. D.; Nguyen, M. T. T.; Le, H. V.; Nguyen, D. N.; Truong, Q. D.; Tran, P. D. Gold Nanoparticles as an Outstanding Catalyst for the Hydrogen Evolution Reaction. Chem. Commun. 2018, 54, 3363-3366

(9) Ofir, Y.; Samanta, B.; Rotello, V. M. Polymer and Biopolymer Mediated Self-Assembly of Gold Nanoparticles. Chem. Soc. Rev. 2008, 37, 1814-1825.

(10) Corbierre, M. K.; Cameron, N. S.; Sutton, M.; Mochrie, S. G. J.; Lurio, L. B.; Rühm, A.; Lennox, R. B. Polymer-Stabilized Gold Nanoparticles and Their Incorporation into Polymer Matrices. J. Am. Chem. Soc. 2001, 123, 10411-10412.

(11) Cheval, N.; Gindy, N.; Flowkes, C.; Fahmi, A. Polyamide 66 Microspheres Metallised with in Situ Synthesised Gold Nanoparticles for a Catalytic Application. Nanoscale Res. Lett. 2012, 7, No. 182.

(12) Shah, D.; Kaur, H. Resin-Trapped Gold Nanoparticles: An Efficient Catalyst for Reduction of Nitro Compounds and SuzukiMiyaura Coupling. J. Mol. Catal. A: Chem. 2014, 381, 70-76.

(13) Praharaj, S.; Nath, S.; Ghosh, S. K.; Kundu, S.; Pal, T. Immobilization and Recovery of $\mathrm{Au}$ Nanoparticles from Anion Exchange Resin: Resin-Bound Nanoparticle Matrix as a Catalyst for the Reduction of 4-Nitrophenol. Langmuir 2004, 20, 9889-9892.

(14) Kumar Vemula, P.; Aslam, U.; Ajay Mallia, V.; John, G. In Situ Synthesis of Gold Nanoparticles Using Molecular Gels and Liquid Crystals from Vitamin-C Amphiphiles. Chem. Mater. 2007, 19, 138140.

(15) Lahtinen, E.; Kivijärvi, L.; Tatikonda, R.; Väisänen, A.; Rissanen, K.; Haukka, M. Selective Recovery of Gold from Electronic Waste Using 3D-Printed Scavenger. ACS Omega 2017, 2, 7299-7304.

(16) Kamyshny, A.; Ben-Moshe, M.; Aviezer, S.; Magdassi, S. Ink-Jet Printing of Metallic Nanoparticles and Microemulsions. Macromol. Rapid Commun. 2005, 26, 281-288.

(17) Fantino, E.; Chiappone, A.; Roppolo, I.; Manfredi, D.; Bongiovanni, R.; Pirri, C. F.; Calignano, F. 3D Printing of Conductive Complex Structures with In Situ Generation of Silver Nanoparticles. Adv. Mater. 2016, 28, 3712-3717.

(18) Lahtinen, E.; Kukkonen, E.; Jokivartio, J.; Parkkonen, J.; Virkajärvi, J.; Kivijärvi, L.; Ahlskog, M.; Haukka, M. Preparation of Highly Porous Carbonous Electrodes by Selective Laser Sintering ACS Appl. Energy Mater. 2019, 2, 13141318 DOI: 10.1021/ acsaem. 8 b0 01881 .

(19) Shi, D.; Gibson, I. Material Properties and Fabrication Parameters in Selective Laser Sintering Process. Rapid Prototyping J. 1997, 3, 129-136.

(20) Shirazi, S. F. S.; Gharehkhani, S.; Mehrali, M.; Yarmand, H.; Metselaar, H. S. C.; Adib Kadri, N.; Osman, N. A. A. A Review on Powder-Based Additive Manufacturing for Tissue Engineering: Selective Laser Sintering and Inkjet 3D Printing. Sci. Technol. Adv. Mater. 2015, 16, No. 33502.

(21) Fina, F.; Goyanes, A.; Gaisford, S.; Basit, A. W. Selective Laser Sintering (SLS) 3D Printing of Medicines. Int. J. Pharm. 2017, 529, 285-293.

(22) Dizon, J. R. C.; Espera, A. H.; Chen, Q.; Advincula, R. C. Mechanical Characterization of 3D-Printed Polymers. Addit. Manuf. 2018, 20, 44-67.

(23) Lahtinen, E.; Hänninen, M. M.; Kinnunen, K.; Tuononen, H. M.; Väisänen, A.; Rissanen, K.; Haukka, M. Porous 3D Printed Scavenger Filters for Selective Recovery of Precious Metals from Electronic Waste. Adv. Sustainable Syst. 2018, 2, No. 1800048.

(24) Lahtinen, E.; Precker, R. L. M.; Lahtinen, M.; Hey-Hawkins, E.; Haukka, M. Selective Laser Sintering of Metal-Organic Frameworks: 
Production of Highly Porous Filters by 3D Printing onto a Polymeric Matrix. ChemPlusChem 2019, 84, 222-225.

(25) Yang, M.-Q.; Pan, X.; Zhang, N.; Xu, Y.-J. A Facile One-Step Way to Anchor Noble Metal ( $\mathrm{Au}, \mathrm{Ag}, \mathrm{Pd}$ ) Nanoparticles on a Reduced Graphene Oxide Mat with Catalytic Activity for Selective Reduction of Nitroaromatic Compounds. CrystEngComm 2013, 15, 6819-6828.

(26) Li, J.; Liu, C.; Liu, Y. Au/Graphene Hydrogel: Synthesis, Characterization and Its Use for Catalytic Reduction of 4-Nitrophenol. J. Mater. Chem. 2012, 22, 8426-8430.

(27) Kuroda, K.; Ishida, T.; Haruta, M. Reduction of 4-Nitrophenol to 4-Aminophenol over Au Nanoparticles Deposited on PMMA. J. Mol. Catal. A: Chem. 2009, 298, 7-11.

(28) Liu, X.; Xu, H.; Xia, H.; Wang, D. Rapid Seeded Growth of Monodisperse, Quasi-Spherical, Citrate-Stabilized Gold Nanoparticles via $\mathrm{H}_{2} \mathrm{O}_{2}$ Reduction. Langmuir 2012, 28, 13720-13726.

(29) International Centre for Diffraction Data, ICDD-PDF4+, Release 2018, 12 CampusBoulevard, Newton Square, Pennsylvania, 2018.

(30) Degen, T.; Sadki, M.; Bron, E.; König, U.; Nénert, G. The HighScore Suite. Powder Diffr. 2014, 29, S13-S18. 